\title{
Memory functioning in obsessive-compulsive disorder
}

\author{
M. Abbruzzese, L. Bellodi, S. Ferri and S. Scarone \\ Psychiatric Branch, Department of Biomedical and Technological Sciences, University of \\ Milan Medical School and Istituto Scientifico H.S. Raffaele, Milan, Italy \\ Correspondence to: M. Abbruzzese, Psychiatric Branch, Department of Biomedical and \\ Technological Sciences, Istituto Scientifico H.S. Raffaele, via Prinetti 29, \\ 20127 Milano, Italy
}

\begin{abstract}
A number of studies have reported neuropsychological deficits in obsessive-compulsive disorder (OCD). These have mainly implicated frontal or temporal dysfunction. In this study, we compared the performances of $O C D$ patients and normal subjects using a factorial interpretation of the Wechsler Memory Scale. Our results do not demonstrate significant memory impairment in OCD patients but point to the possibility of frontal lobe dysfunction as a factor in the pathophysiology of OCD.
\end{abstract}

Keywords: Memory - Neuropsychology - Obsessive-compulsive disorder (OCD) - Wechsler Memory Scale (WMS)

\section{INTRODUCTION}

Patients with obsessive-compulsive disorder (OCD) sometimes complain of memory disturbance. Mnesic functions have classically been associated with left temporal lobe dysfunction (Delaney et al., 1980) but the complex circuits which connect limbic structures to the frontal lobe are also of considerable importance (Fuster, 1989). According to the classical model (Mishkin, 1982), memory seems to be related to two pathways, the first involving the amygdala and the connections with the medial frontal cortex, the second involving the hippocampus, anterior thalamic nuclei and their connection with the DLPC and temporal cortex. Both systems are thought to be of importance in recognition memory (Bachevalier and Mishkin, 1986), but DLPC dysfunction has also been associated with deficits in selective association and immediate learning (Sass et al., 1987; Helkala et al., 1988) and recall memory impairment in DLPC damaged patients (Grafman et al., 1986) as well as in schizophrenics (Goldberg et al., 1989, 1990).

A link between frontal lobe dysfunction and cognitive deficits has been reported in OCD (Flor-Henry, 1974, 1983; Malloy, 1987; Modell et al., 1989; Rosenthal and Fedio, 1975). More recent studies have also identified non-verbal memory deficits (Christensen et al., 1992), difficulties in neuropsychological tasks involving spatial abilities (Hymas et al., 1991) and in reproduction of complex figures (Cox et al., 1989). Impairment of visual, memory and intellectual processes on the Luria-Nebraska battery (Moses et al., 1983; Bellini et al., 1989), spatial- perceptual abnormalities (Behar et al., 1984), impaired performance in the Wisconsin Card Sorting Test (Grant and Berg, 1948; Lezak, 1983; Hymas et al., 1991) and deficits on tasks involving attention (Insel et al., 1983) have also been reported.

The Wechsler Memory Scale (WMS; Wechsler, 1945) is a useful and well-standardized instrument for global memory assessment. Poor performance on the WMS has been described in normal volunteers with checking behavior (Sher et al., 1984), in a subgroup of OCD patients (Sher et al., 1989), and in OCD children (Behar et al., 1984).

In this study we evaluate the WMS performances in 43 OCD patients compared with 39 sex, age, handedness and education matched normal subjects. We used a factorial WMS profile rather than individual performance in terms of raw subtest scores or the global memory level (Quotient of Memory). This evaluation of the WMS scores was proposed as a 'more rational scale of measurement' (KearColwell, 1973) to emphasize the relationship between single factorial score and selective mnesic performance.

\section{SUBJECTS AND METHODS}

Eighty-two subjects (43 OCD patients and 39 normal subjects matched for age, sex, educational level and handedness) participated in the investigation. Table I shows the clinical and demographic characteristics of the sample. The 43 OCD patients were all recruited from the Anxiety 
TABLE I. Clinical and demographic characteristics of the sample

\begin{tabular}{lccccc}
\hline & \multicolumn{2}{c}{$\begin{array}{c}\text { OCD } \\
(n=43)\end{array}$} & & \multicolumn{2}{c}{$\begin{array}{c}\text { Controls } \\
(n=39)\end{array}$} \\
\cline { 2 - 3 } \cline { 6 - 7 } & Mean & $($ S.D. $)$ & & Mean & $($ S.D. $)$ \\
\hline Age (years) & 30.8 & $(9.9)$ & & 30.4 & $(6.7)^{\star}$ \\
Education (years) & 10.3 & $(3.5)$ & & 11.7 & $(4.1)^{\star *}$ \\
Onset & 20.6 & $(7.8)$ & & & \\
Duration of illness & 10.4 & $(8.5)$ & & & \\
\hline Sex & $\mathrm{M}=20$ & $\mathrm{~F}=23$ & & $\mathrm{M}=23$ & $\mathrm{~F}=16^{\star \star *}$ \\
\hline
\end{tabular}

${ }^{*}$ ANOVA: $F(1,80)=0.05, p=$ N.S.

** ANOVA: $F(1,80)=2.90, p=$ N.S.

${ }^{\star \star \star}$ Chi-square $=0.83$ with $2 \mathrm{df}, p=0.36$ (Yates corrected).

TABLE II. Clinical characteristics of the OCD sample

\begin{tabular}{lcc}
\hline & Male & Female \\
\hline Washers & 5 & 7 \\
Checkers & 9 & 3 \\
Mental checkers & 2 & 6 \\
Mixed & 4 & 7 \\
\hline
\end{tabular}

Chi-square $=5.97$ with $3 \mathrm{df}, p=0.12$

\begin{tabular}{lcc}
\hline BOCS scores & Mean & S.D. \\
\hline Obsessions & 13.5 & 3.4 \\
Compulsions & 13.2 & 3.4 \\
Total score & 26.7 & 5.7 \\
\hline
\end{tabular}

In-patients Unit at the Psychiatric Branch of S. Raffaele Hospital. Two psychiatrists assessed the diagnosis by means of the computerized version of DIS-R (Robins et al., 1989) according to the DSM-III-R criteria (APA, 1987). In addition, OCD symptomatology was assessed using the Yale-Brown Obsessive-Compulsive Scale (YBOCS) (Goodman et al., 1989a,b). At the time of their neuropsychological evaluation, all the OCD patients had been treated with fluvoxamine maleate (mean dosage of $234 \pm 35 \mathrm{mg} /$ day) for at least 2 months. No patients had taken benzodiazepines in the 2 weeks preceding the tests. Table II shows the phenomonology of OCD patients.

The 39 normal subjects were recruited from hospital employees and nursing staff; the inclusion criteria for recruitment were a personal negative history of neurological and psychiatric illnesses, alcohol abuse, history of documented head injuries, loss of consciousness, neurosurgical treatment or perinatal trauma. Before the tests all subjects were submitted to a complete physical and neurological examination in order to exclude any somatic illness. All subjects were right handed as judged by a handedness questionnaire (Raczkowsky et al., 1974). Informed consent about the purposes of the study was obtained from each subject before testing.

\section{Testing procedures}

The WMS is a widely used task for assessing global memory impairment. The WMS-R was administered by a trained neuropsychologist in a quiet laboratory according to standard procedures (Wechsler, 1945). The time to administer the complete task never exceeded $30 \mathrm{~min}$. The examiner was not blind to diagnosis. The WMS battery is based on seven subtests: Orientation, Information, Mental Control, Logical Memory, Digit Span, Visual Reproduction and Associate Learning. According to the model proposed by Kear-Colwell (Kear-Colwell, 1973), a more rational WMS interpretation can be made by means of factor scores rather than the raw subtest scores or the Quotient of Memory. This model is based on the following formulae for converting subtest scores to factor scores:

Factor I $=-0.27+(0.25 \times$ Logical Memory $)+$ $(0.19 \times$ Visual Reproduction $)+(0.21 \times$ Associate Learning)

Factor II $=-1.80+(0.28 \times$ Information $)+(-0.34 \times$ Orientation $)+(0.43 \times$ Mental Control $)+$ (0.45 $\times$ Digit Span)

Factor III $=-9.68+(0.78 \times$ Information $)+(2.34 \times$ Orientation)

Factor I concerns immediate learning and recall abilities, Factor II includes attention and concentration and Factor III orientation and long-term information recall (Skilbeck and Woods, 1980).

Our group has recently demonstrated the validity of this approach in the neuropsychological evaluation of mental disorders (Colombo et al., 1993).

\section{Statistical analysis}

Analysis of variance (ANOVA) was performed in order to assess the groups' differences on the three WMS factors. Pearson's product-moment correlations between WMS and BOCS scores were produced to evaluate the relationship between test performances and symptom severity. Kruskal-Wallis one-way ANOVA was performed to compare the differences between the OCD subtypes.

\section{RESULTS}

Table III summarizes the WMS results in the OCD and control groups. Among the WMS factor scores, only Fac-

TABLE III. WMS performances in OCD patients and normal subjects

\begin{tabular}{lcccccc}
\hline & \multicolumn{2}{c}{ OCD } & & \multicolumn{2}{c}{ Normal subjects } \\
\cline { 2 - 3 } \cline { 6 - 7 } & Mean & (S.D.) & & Mean & (S.D.) \\
\hline Factor I & 6.78 & 1.74 & & 7.34 & 1.76 \\
Factor II & 6.06 & 1.45 & & 6.31 & 1.58 \\
Factor III & 5.66 & 1.31 & & 6.50 & $0.40^{\star \star}$ \\
\hline
\end{tabular}

** $p<0.01$. 
tor III was significantly lower in the OCD patients $[\mathrm{F}(1,80)=14.75, p<0.002]$. No significant differences were found in OCD subtypes with regard to the other two WMS factors. No sex differences were found in the three WMS factor scores. No significant correlations at the $p=0.01$ level were found between OCD symptomatology (BOCS scores) and WMS factor scores.

\section{DISCUSSION}

The results of this investigation reveal a WMS profile in which the OCD patients show selective mnesic deficits when compared with normal subjects. Age, gender, educational level and handedness differences between the groups were not statistically significant, so it is reasonable to suppose that these variables do not play a critical role in the WMS performances. The OCD patients showed poorer performances when compared with normal subjects in the WMS Factor III, which has been related to orientation and long-term information recall (Skilbeck and Woods, 1980).

Even though we have utilized a standardized interpretation of the WMS by means of a factorial model, separate analysis of the two subtests (Information and Orientation) subsumed under Factor III may be useful in order to clarify their neuropsychological meaning. The Information subtest can be considered as a measure of verbal skills and remote memory; in brain injured populations, information is the least affected of the WAIS and WMS subtests (O'Brien and Lezak, 1981) and has been considered a poor predictor of left hemisphere involvement (Smith, 1966; Spreen and Benton, 1965). Therefore, these findings cannot support the hypothesis of localized cerebral malfunctioning. As far as the Orientation subitem is concerned, some authors consider impairment an expression of frontal dysfunction (Benton, 1968; Joslyn and Hutzell, 1979), and marked impairment in Orientation can be found in cases of bilateral lesions of frontal lobes. Orientation impairment is a frequent symptom of brain disease involving the cortical areas and is closely related to attention deficits (McGhie, 1969; Eisdorfer and Cohen, 1980). OCD deficits on the orientation subitem may be related therefore to mild disturbances in attention, resulting from frontal lobe dysfunction (Posner and Petersen, 1990). This finding appears to be in agreement with a hypothesis of frontal lobe involvement in OCD (Flor-Henry et al., 1979; Modell et al., 1989). It is also possible that the everyday problems reported by OCD patients may be an expression of attention and orientation problems.

We have not found differences in WMS performances between checkers or washers, as reported elsewhere (Sher et al., 1984), or a significant correlation between memory abilities and clinical symptomatology. These findings suggest that in terms of memory it is difficult to differentiate OCD patients into distinct clinical subgroups. We have also failed to find significant correlations between symptom severity (i.e. time spent in compulsions or obsessions) or the duration of illness and WMS performances.

The results obtained suggest that memory deficits may occur in OCD and that frontal rather than temporal dysfunction seems to be principally involved. This finding appears to be consistent with the recent biological models which attribute a fundamental role to pathways connecting the frontal lobe to subcortical regions in OCD psychophysiology (Wise and Rapoport, 1989).

\section{REFERENCES}

American Psychiatric Association (1987) Diagnostic and Statistical Manual, 3rd edn, revised (DSM III-R). American Psychiatric Association Press, Washington, DC.

Bachevalier J and Mishkin M (1986) Visual recognition impairment follows ventromedial but not dorsolateral prefrontal lesions in monkeys. Behavioral and Brain Research, 20, 249-261.

Behar D, Rapoport JL, Berg CJ, Denkla MB, Mann L, Cox C, Fedio P, Zahn T and Wolfman MG (1984) Computerized tomography and neuropsychological test measures in adolescents with obsessive-compulsive disorder. American Journal of Psychiatry, 141, 363-368.

Bellini L, Massironi R, Palladino F, Locatelli M, Gambini O and Scarone S (1989) Neurofunctional assessment of Obsessive Compulsive Disorder: A neuropsychological study. Research Communications in Psychology, Psychiatry and Behavior, 14, 73-83.

Benton AL (1968) Differential behavioral effects in frontal lobe disease. Neuropsychologia, 6, 53-60.

Christensen KJ, Kim SW, Dysken MW and Hoover KM (1992) Neuropsychological performances in obsessive-compulsive disorder. Biological Psychiatry, 31, 4-18.

Colombo C, Abbruzzese M, Livian S, Scotti G, Locatelli M, Bonfanti A and Scarone S (1993) Memory functions and temporal-limbic morphology in Schizophrenia. Psychiatry Research, in press.

Cox CS, Fedio P and Rapoport JL (1989) Neuropsychology of obsessive-compulsive adolescents. In: Obsessive-Compulsive Disorder in Children and Adolescents (Ed. JL Rapoport), Ch. 19, pp. 327-344. American Psychiatric Press Inc., Bethesda, MD.

Delaney RC, Rosen AJ, Mattson RH and Novelly RA (1980) Memory function in focal epilepsy: a comparison of nonsurgical, unilateral temporal lobe and frontal lobe samples. Cortex, 16, 103-117.

Eisdorfer C and Cohen D (1980) Diagnostic criteria for primary neuronal degeneration of the Alzheimer's type. Journal of Family Practice, 11, 553-557.

Flor-Henry P (1983) Cerebral Basis of Psychopathology. John Wright, Boston.

Flor-Henry P, Yeudall LT, Koles ZJ et al. (1979) Neuropsychological and power spectral EEG investigations of obsessive-compulsive syndrome. Biological Psychiatry, 14, 119-130.

Fuster JM (1989) The Prefrontal Cortex. Raven Press, New York.

Goldberg TE, Weinberger DR, Pliskin NH, Berman KF and Podd MH (1989) Recall memory deficits in schizophrenia. A 
possible manifestation of prefrontal dysfunction. Schizophrenia Research, 2, 251-257.

Goldberg TE, Kelsoe JR, Weinberger DR et al. (1990) Performances of schizophrenic patients on putative neuropsychological tests of frontal lobe function. International Journal of Neuroscience, 42, 51-58.

Goodman WK, Price LH, Rasmussen SA, Mazure C, Fleischmann RL, Hill CL, Heninger GR and Charney DS (1989a) The Yale-Brown Obsessive Compulsive Scale. I. Development, use, reliability. Archives of General Psychiatry, 46, 1006-1011.

Goodman WK, Price LH, Rasmussen SA, Mazure C, Delgado P, Heninger GR and Charney DS (1989b) The Yale-Brown Obsessive Compulsive Scale. II. Validity. Archives of General Psychiatry, 46, 1012-1016.

Grafman J, Vance SC, Weingarner H, Salazar AM and Amir D (1986) The effects of lateralized frontal lesions on mood regulation. Brain, 109, 1127-1148.

Grant DA and Berg EA (1948) A behavioral analysis of degree of reinforcement and ease of shifting to new responses in a Weigl-type card sorting problem. Journal of Experimental Psychology, 38, 404-411.

Helkala EL, Laulumma V and Soininen H (1988) Recall and Recognition memory in patients with Alzheimer's and Parkinson's diseases. Annals of Neurology, 24, 214-217.

Hymas N, Lees A, Bolton D, Epps K and Head D (1991) The neurology of obsessional slowness. Brain, 114, 2203-2233.

Insel TR, Donnelly EF, Lalakea ML, Alterman IS and Murphy DL (1983) Neurological and neuropsychological studies of patients with Obsessive-compulsive disorder. Biological Psychiatry, 18, 741-751.

Joslyn D and Hutzell RR (1979) Temporal disorientation in schizophrenic and brain-damaged patients. American Journal of Psychiatry, 136, 1220-1222.

Kear-Colwell JJ (1973) The structure of the Wechsler Memory Scale and its relationship to brain damage. Journal of Social and Clinical Psychology, 12, 384-392.

Lezak MD (1983) Neuropsychological Assessment, 2nd ed. Oxford University Press, New York.

Malloy P (1987) Frontal lobe dysfunction in obsessive-compulsive disorder. In: The Frontal Lobes Revisited (Ed. E Perecman). IRBN Press.

McGhie A (1969) Psychological aspects of attention and its disorders. In: Handbook of Clinical Neurology, Vol. 3 (Eds PJ Vinken and GW Bruyn). Wiley, New York.

Mishkin M (1982) A memory system in the monkey. In: The Neuropsychology of Cognitive Function (Eds DE Broadbent and L Weiskantz). The Royal Society, London.

Modell JG, Mountz JM, Curtis G and Gredel JF (1989) Neurophysiologic dysfunction in basal ganglia/limbic striatal and thalamocortical circuits as a pathogenetic mechanism of obsessive-compulsive disorder. Journal of Neuropsychiatry, 1, 27-36.

Moses YA, Golden CJ, Ariel L and Gustavson J (1983) Interpretation of the Lurja-Nebraska Neuropsychological Battery, pp. 63-84. Grune \& Stratton, New York.

O'Brien K and Lezak MD (1981) Long term improvements in intellectual function following brain injury. Paper presented at the fourth European conference of the International Neuropsychological Society, Bergen, Norway.

Posner MI and Petersen SE (1990) The attention system of the human brain. Annual Review of Neurosciences, 13, 25-42.

Raczkowsky D, Kalat JW, Nebes R (1974) Reliability and validity of some handedness questionnaire items. Neuropsychologia, 12, 43-48.

Robins LN, Helzer J, Cottler L and Goldring E (1989) Diagnostic Interview Schedule, Version III-R (DIS-III-R). Washington University School of Medicine, St Louis.

Rosenthal LS and Fedio P (1975) Recognition thresholds in central and lateral visual fields following temporal lobectomy. Cortex, 11, 217-229.

Sass KJ, Tredeau A and Spencer D (1987) Memory impairments associated with mass lesions of the frontal lobe. Journal of Clinical and Experimental Neuropsychology, 9, 79.

Sher KJ, Frost RO, Kushner M, et al. (1989) Memory deficits in compulsive checkers: Replication and extension in a clinical sample. Behavioural Research and Therapy, 27, 65-69.

Sher KJ, Mann B and Frost RO (1984) Cognitive dysfunction in compulsive checkers: further explorations. Behavioural Research and Therapy, 22, 493-502.

Skilbeck OE and Woods RT (1980) The factorial structures of the Wechsler Memory Scale: samples of neurological and psychogeriatric patients. Journal of Clinical Neuropsychology, 2, 293-300.

Smith A (1966) Certain hypothesized hemispheric differences in languages and visual functions in human adults. Cortex, $\mathbf{1}$, 109-126.

Spreen O and Benton AL (1965) Comparative studies of some psychological tests for cerebral damage. Journal of Nervous and Mental Disease, 140, 323-333.

Wechsler D (1945) A standardized memory scale for clinical use. Journal of Psychology, 19, 87-95.

Wise SP and Rapoport JL (1989) Obsessive-compulsive disorder: is it basal ganglia dysfunction? In: Obsessive-Compulsive Disorder in Children and Adolescents (Ed. JL Rapoport), Ch. 19, pp. 327-344. American Psychiatric Press Inc., Bethesda, MD.

(Received 30 April 1993; accepted 18 May 1993) 


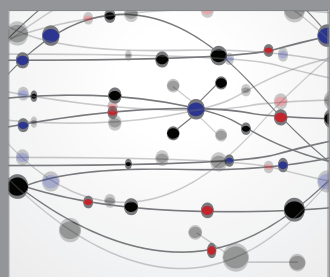

The Scientific World Journal
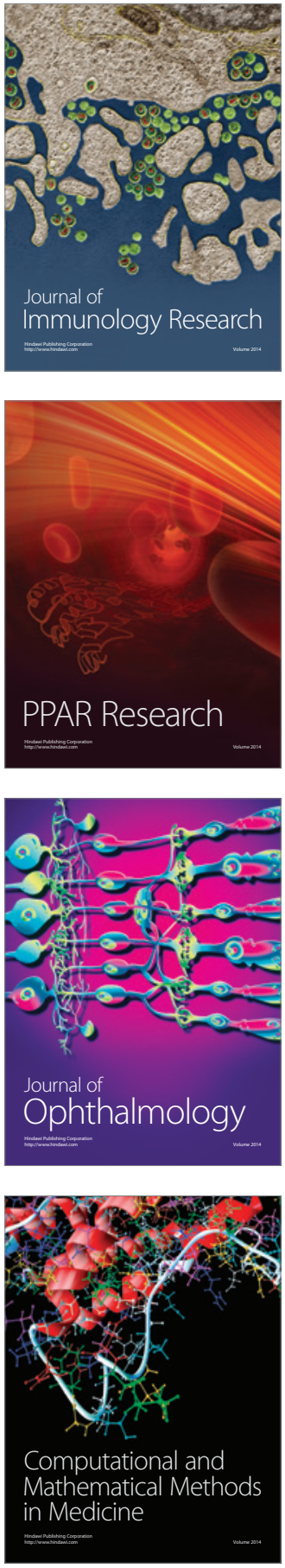

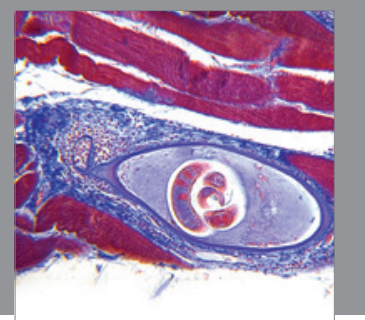

Gastroenterology

Research and Practice
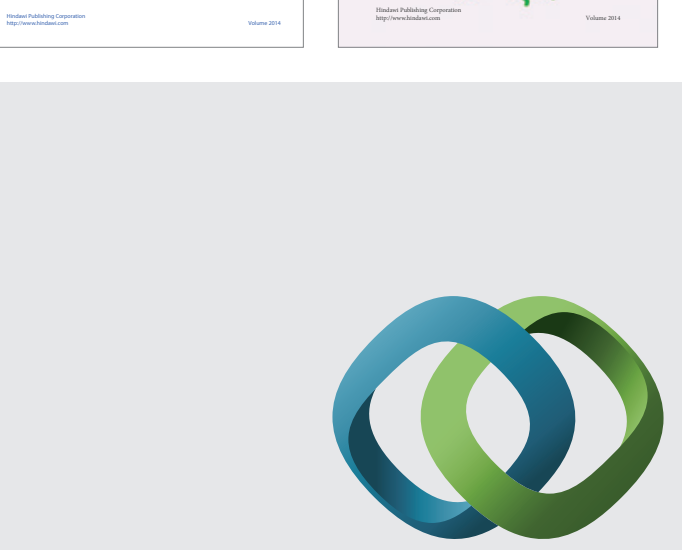

\section{Hindawi}

Submit your manuscripts at

http://www.hindawi.com
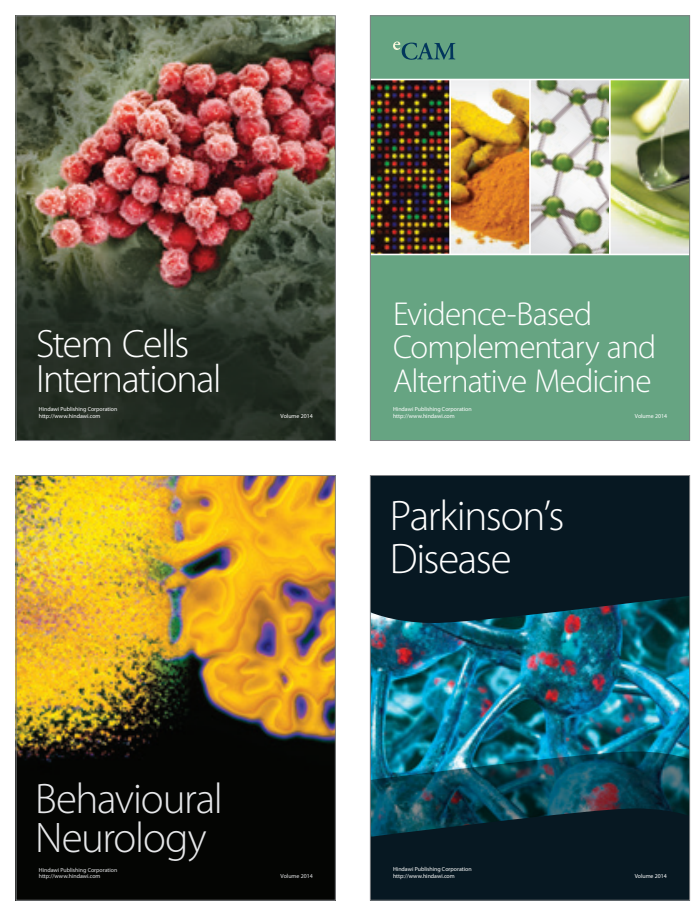

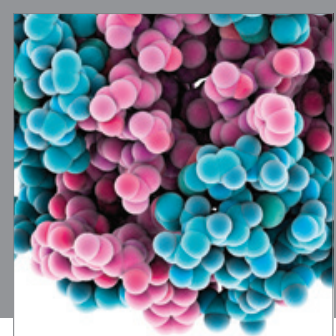

Journal of
Diabetes Research

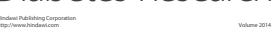

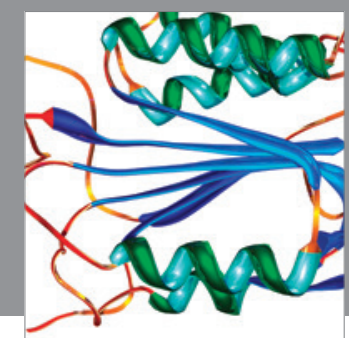

Disease Markers
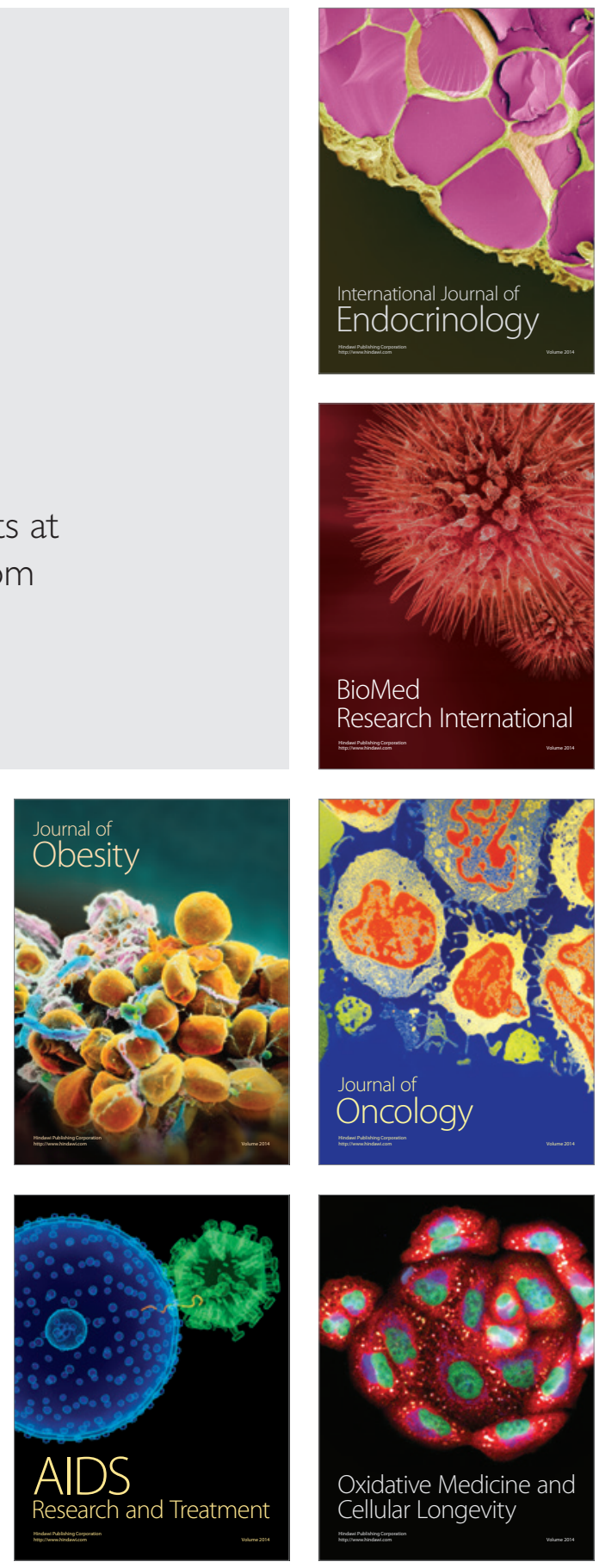